\title{
Article \\ Microstructure Evolution of Graphene and the Corresponding Effect on the Mechanical/Electrical Properties of Graphene/Cu Composite during Rolling Treatment
}

\author{
Ziyang Xiu ${ }^{1,2, \dagger}$, Boyu Ju ${ }^{2, *,+}\left(\mathbb{D}\right.$, Junhai Zhan ${ }^{3}$, Ningbo Zhang ${ }^{4}$, Zhijun Wang ${ }^{2}$, Yong Mei ${ }^{2,5, *}$, Jinming Liu ${ }^{6, *}$, \\ Yuhan Feng ${ }^{5, *}$, Yixin Guo ${ }^{2}$, Pengchao Kang ${ }^{2, *}$, Qiang Zhang ${ }^{2, *}$ and Wenshu Yang ${ }^{2, *(\mathbb{D})}$ \\ 1 State Key Laboratory of Advanced Welding and Joining, Harbin Institute of Technology, \\ Harbin 150001, China; xiuzy@hit.edu.cn \\ 2 School of Materials Science and Engineering, Harbin Institute of Technology, Harbin 150001, China; \\ hitzhijun@gmail.com (Z.W.); gyx082339@icloud.com (Y.G.) \\ 3 Shanghai Aerospace System Engineering Research Institute, Shanghai 201108, China; JPY_mat@163.com \\ 4 Aerospace Research Institute of Materials \& Processing Technology, Beijing 100076, China; \\ zhangnbathit@163.com \\ 5 School of Astronautics, Harbin Institute of Technology, Harbin 150001, China \\ 6 Defense Engineering of Academy of Military Sciences, PLA Academy of Military Sciences, \\ Beijing 100036, China \\ * Correspondence: juboyu_hit@163.com (B.J.); Meiyong1990@126.com (Y.M.); Liujm1025@outlook.com (J.L.); \\ luckyfengyuhan@163.com (Y.F.); kangpc@hit.edu.cn (P.K.); zhang_tsiang@hit.edu.cn (Q.Z.); \\ yws001003@163.com (W.Y.) \\ $\dagger$ These authors contributed equally to this work.
}

\section{check for}

updates

Citation: Xiu, Z.; Ju, B.; Zhan, J.; Zhang, N.; Wang, Z.; Mei, Y.; Liu, J.; Feng, Y.; Guo, Y.; Kang, P.; et al. Microstructure Evolution of Graphene and the Corresponding Effect on the Mechanical/Electrical Properties of Graphene/Cu Composite during Rolling Treatment. Materials 2022, 15, 1218. https:// doi.org/10.3390/ma15031218

Academic Editor: Dina Dudina

Received: 28 December 2021

Accepted: 4 February 2022

Published: 6 February 2022

Publisher's Note: MDPI stays neutral with regard to jurisdictional claims in published maps and institutional affiliations.

Copyright: (C) 2022 by the authors. Licensee MDPI, Basel, Switzerland. This article is an open access article distributed under the terms and conditions of the Creative Commons Attribution (CC BY) license (https:// creativecommons.org/licenses/by/ $4.0 /)$.

\begin{abstract}
Rolling enables the directional alignment of the reinforcements in graphene/Cu composites while achieving uniform graphene dispersion and matrix grain refinement. This is expected to achieve a breakthrough in composite performance. In this paper, the process parameters of rolling are investigated, and the defects, thickness variations of graphene and property changes of the composite under different parameters are analyzed. High-temperature rolling is beneficial to avoid the damage of graphene during rolling, and the prepared composites have higher electrical conductivity. The properties of graphene were investigated. Low-temperature rolling is more favorable to the thinning and dispersion of graphene; meanwhile, the relative density of the composites is higher in the lowtemperature rolling process. With the increase of rolling deformation, the graphene defects slightly increased and the number of layers decreased. In this paper, the defect states of graphene and the electrical conductivity with different rolling parameters is comprehensively investigated to provide a reference for the rolling process of graphene/copper composites with different demands.
\end{abstract}

Keywords: graphene/cu composite; rolling treatment; graphene dispersion; graphene defects

\section{Introduction}

$\mathrm{Cu}$ metals, alloys, and composites are widely used in industrial production. $\mathrm{Cu}$ has excellent electrical and thermal conductivity, as well as good processability and corrosion resistance, second only to Ag [1,2]. They play a vital role in key fields such as electronic packaging, microelectronics industry, national defense, and aerospace [3-5]. Graphene is an emerging reinforcement material. Due to the unique two-dimensional structure of graphene, it has ultra-high thermal conductivity (up to $5300 \mathrm{~W} /(\mathrm{mK})$ ) and excellent mechanical properties [6,7], and has been made a good selection for different industrial applications [8-10]. Graphene nanoplates (GNPs) are used as reinforcements and added to the pure copper metal matrix to prepare GNPs/Cu composites. Theoretically, they can retain the high electrical conductivity and high thermal conductivity of the $\mathrm{Cu}$ metal material while having good mechanical properties $[11,12]$. Moreover, graphene/Cu composite 
has good designability and is expected to be applied in the fields of different structures and functional materials [13-15].

However, the current development of graphene/Cu composite faces the following problems. Since graphene is a nano reinforcement, it is very easy to agglomerate after being prepared into a composite, which causes the two-dimensional strengthening characteristics of the graphene to fail to fully play, which reduces the performance [16,17]. In addition, graphene is easily damaged during material processing $[18,19]$. The defect causes a substantial decrease in the electrical conductivity of graphene.

The uniform dispersion of graphene in the metal matrix can be achieved through the deformation of the composites. Shao et al. [20,21] found that the hot extrusion process can make the graphene oriented in the $\mathrm{Al}$ matrix. Under the action of shearing, the graphene was also twisted, bent, and opened by shearing between layers, so that the graphene was further dispersed. The obtained composite had a tensile strength of $500 \mathrm{MPa}$, which was $40 \%$ higher than the performance of the $\mathrm{Al}$ matrix. Wu et al. [22] studied the effect of multi-pass extrusion on graphene/6063Al composites. It is found that after multiple extrusions, graphene had an obvious interlayer slip, and fewer graphene nanoplates were peeled off from the thick graphene layer. After 3-cycle extrusion, the plasticity of GNPs $/ 6063 \mathrm{Al}$ composites increased from $7 \%$ to $13 \%$ without any decrease in strength. The improvement of composite performance comes from the fact that graphene is less layered and redispersed after multiple extrusions so that the strengthening ability of graphene can be further exerted. Huang et al. [23] studied the properties of rolled graphene/Al composites at different temperatures and found that when the temperature is below $500{ }^{\circ} \mathrm{C}$, the tensile strength of the material gradually increases as the temperature rises. When the rolling temperature exceeded $500{ }^{\circ} \mathrm{C}$, the mechanical properties of the material decreased as the temperature increased, and a large amount of reaction product $\mathrm{Al}_{4} \mathrm{C}_{3}$ was observed at the interface.

Wang et al. [24] reported the peeling behavior of graphene during the rolling process. It was found that the graphene structure evolved according to the following process: firstly, it was aligned along the rolling direction, then broken into small pieces, and finally exfoliated into a few layers of graphene. The exfoliated graphene provided an additional contribution to the strength and plasticity of the composite. Korznikova et al. [25] studied the graphene/Cu composites consolidation by means of its high-pressure torsion (HPT). It was found that under the action of deformation, the grains of the $\mathrm{Cu}$ matrix were refined, and the graphene was more uniformly dispersed. The elongation of the composite decreased from $15 \%$ to $4 \%$ after deformation, but the hardness increased by almost $30 \%$. Yao et al. [26] investigated the variation of $\mathrm{Cu} / \mathrm{C}$ composites during accumulative rollbonding (ABR). Results showed that ARB can remarkably decrease the size of graphite and improve the dispersion of graphite in the $\mathrm{Cu}$ matrix. Tiwari et al. [27] investigated graphene/ $\mathrm{Al}$ composites prepared by ARB and found that the tensile strength and hardness of the composites were enhanced by $25 \%$ and $20 \%$, respectively, which was attributed to the fraction of high angle grain boundaries enhancement and homogeneous dispersion of graphene. Liu et al. [28] investigated the organization of Graphene nanosheets/Cu composites after ARB treatment and found the average spacing of high-angle boundaries along the normal direction was finer than that of the ARBed $\mathrm{Cu}$. In addition, high-density deformation-twins with grain sizes of 50-70 $\mathrm{nm}$ are present at the interface.

The parameters of the deformation have an important influence on the dispersion and deformation of graphene in the matrix, but the rules are still unclear. However, the research on the specific effects of deformation temperature and deformation on the structure and properties of the composite is not comprehensive enough.

In this work, the microstructural evolution behavior of graphene under different rolling parameters was studied. Due to the stable chemical properties of $\mathrm{Cu}$ and no interfacial reaction with graphene, it was convenient to observe the deformation behavior of graphene. Therefore, $\mathrm{Cu}$ was selected as the matrix for preparing composites. In order to clarify the deformation behavior of graphene in the matrix, this paper compre- 
hensively studied the effects of deformation temperature and rolling deformation on graphene/Cu composites. The organization evolution of graphene was studied through Raman spectroscopy, and the mechanical and electrical properties were tested, which provide a reference for subsequent deformation of composite materials.

\section{Materials and Methods}

The graphene used in this experiment was supplied by the Sixth Element Changzhou Materials Technology Co. Ltd. China. The pure $\mathrm{Cu}$ powder used in this study was purchased from Beijing Xingrongyuan Co., Ltd., Beijing, China, with a purity of $99.9 \%$ and an initial particle size of about $3 \mu \mathrm{m}$. The characterization of graphene and $\mathrm{Cu}$ powder is shown in Figure 1. Figure 1a,b show the SEM and Raman characterization of graphene, respectively. Graphene is distributed in flakes. In the Raman characterization, there are mainly three characteristic peaks, namely the D peak at $1350 \mathrm{~cm}^{-1}$, the $G$ peak at $1570 \mathrm{~cm}^{-1}$, and the $2 \mathrm{D}$ peak at $2700 \mathrm{~cm}^{-1}$. The $\mathrm{D}$ peak reflects the asymmetric lattice vibrations, and the $G$ peak reflects the symmetrical lattice vibrations $[29,30]$. The intensity ratio of the $D$ peak and the $G$ peak $\left(\mathrm{I}_{\mathrm{D}} / \mathrm{I}_{\mathrm{G}}\right)$ is often used to reflect the change of graphene defects. $2 \mathrm{D}$ peaks appearing at approximately $2700 \mathrm{~cm}^{-1}$ is related to the number of graphene layers. And the peak position, peak shape, and intensity of 2D peaks can be used to judge the number of graphene layers [31-33]. The smaller the number of graphene layers, the higher the intensity of the 2D peaks and the shift toward lower wavenumbers [34,35].
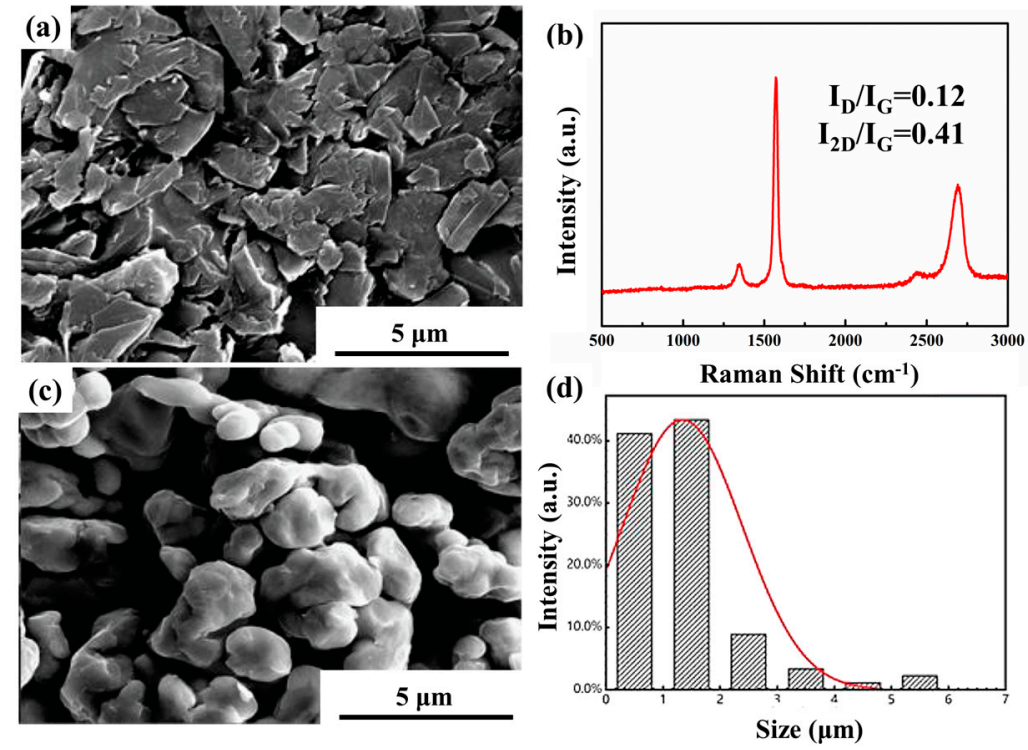

Figure 1. Microstructure characterization of graphene and $\mathrm{Cu}$. (a) SEM of graphene, (b) Raman characterization of graphene, (c) SEM of Cu powders, (d) particle size distribution of $\mathrm{Cu}$ powders.

In this study, a planetary ball mill (YXQM-4L, supplied by Miqi Equipment Co., Ltd., Changsha, China) was used to disperse the graphene, and the ball-milling speed of $120 \mathrm{r} / \mathrm{min}$ for $2 \mathrm{~h}$ was used. The content of graphene is $0.6 \mathrm{wt} . \%$. The mixed graphene-Cu mixed powder is sintered through SPS. The powder mixture of GNPs and $\mathrm{Cu}$ was put into a $40 \mathrm{~mm}$ diameter mold and pressed into preforms at a pressure of $40 \mathrm{MPa}$. The pressure was maintained for $5 \mathrm{~min}$. The mold with the preforms was then placed into the SPS equipment and heated to $1020^{\circ} \mathrm{C}$ at $5{ }^{\circ} \mathrm{C} / \mathrm{min}$ and kept at high temperature for $10 \mathrm{~min}$. The current-to-time ratio (ton:toff) during sintering was 2:1. After the sintering was completed, the sample was cooled to room temperature in the mold with the furnace. The prepared $0.6 \mathrm{wt} . \% \mathrm{GNPs} / \mathrm{Cu}$ composite was subjected to subsequent rolling research.

In this work, a double-roll mill (supplied by Sanye Mould Co., Ltd., Taizhou, China) is used to optimize the deformation of the prepared composite. Under the action of the stresses generated during the rolling process, the $\mathrm{Cu}$ matrix and graphene undergo 
shear deformation. The total thickness reduction (\%) is counted as the amount of downcompression deformation. The $0.6 \mathrm{wt} . \%$ graphene/Cu composite material was cut into $55 \mathrm{~mm} \times 10 \mathrm{~mm} \times 4 \mathrm{~mm}$ rectangular parallelepiped and rolled from the original thickness of $4 \mathrm{~mm}$. The prepared composite is rolled at $20^{\circ} \mathrm{C}, 300^{\circ} \mathrm{C}, 500^{\circ} \mathrm{C}, 700^{\circ} \mathrm{C}$. The deformation amount of each rolling is $10 \%$, and the samples with large deformation amounts are prepared by the method of multiple rolling. The total reduction of multiple rolling is $20-80 \%$. The hardness and electrical conductivity of the composites were subsequently investigated at different rolling temperatures and deformation amounts.

Morphologies of the GNPs/Cu powders and the composites were observed by FEI Quanta 200FEG (supplied by Thermo Fisher Scientific Co., Ltd., Bend, OR, US). Raman analysis was performed on a JY-HR800 laser Raman spectrometer (supplied by HORIBA Ltd., Montpellier, France) using a $532 \mathrm{~nm}$ solid-state laser as an excitation source. The image analysis microhardness of HV-1000IS (provided by Jujing Precision Instrument Manufacturing Co., Ltd. Shanghai, China) was used to test the Vickers hardness of the graphene/Cu composites. In the hardness test, the experimental parameter load is $200 \mathrm{gf}$, the pressure time is $15 \mathrm{~s}$. An FD 102 digital eddy current conductivity meter (supplied by Foster Electronic Technology Co., Ltd., Xiamen, China) was used for the conductivity test. Each sample is randomly measured 5 times at a certain distance, and the average value is obtained. The density of the material was measured by Archimedes' drainage method. The mass of the sample in air and the mass in water are tested separately and the density of the material is calculated according to the formula:

$$
\rho_{m}=\rho_{H 2 O} \frac{m_{1}}{m_{1}-m_{2}}
$$

where $\rho_{m}$ and $\rho_{H 2 O}$ are the densities of the composite and the sample, respectively, and $m_{1}$ and $m_{2}$ are the masses of the composite in air and water, respectively. The relative density is the ratio of the experimental density to the theoretical density of the sample.

\section{Results and Discussion}

\subsection{The Effect of Rolling Temperature on the Structure of Graphene}

The GNPs/Cu composite material was rolled and deformed at rolling temperatures of $20{ }^{\circ} \mathrm{C}, 300{ }^{\circ} \mathrm{C}, 500{ }^{\circ} \mathrm{C}$, and $700{ }^{\circ} \mathrm{C}$, and the total deformation was $80 \%$. Raman characterization of the composite material, the results are shown in Figure 2 . The $\mathrm{I}_{\mathrm{D}} / \mathrm{I}_{\mathrm{G}}$ of graphene in the composite before rolling is 0.20 , and the $\mathrm{I}_{2 \mathrm{D}} / \mathrm{I}_{\mathrm{G}}$ is 0.43 . The state of the graphene in the sintered composite is close to that of the raw graphene because the graphene is less damaged during the preparation processing. The defect content of graphene only increased slightly, and the number of layers did not change significantly.
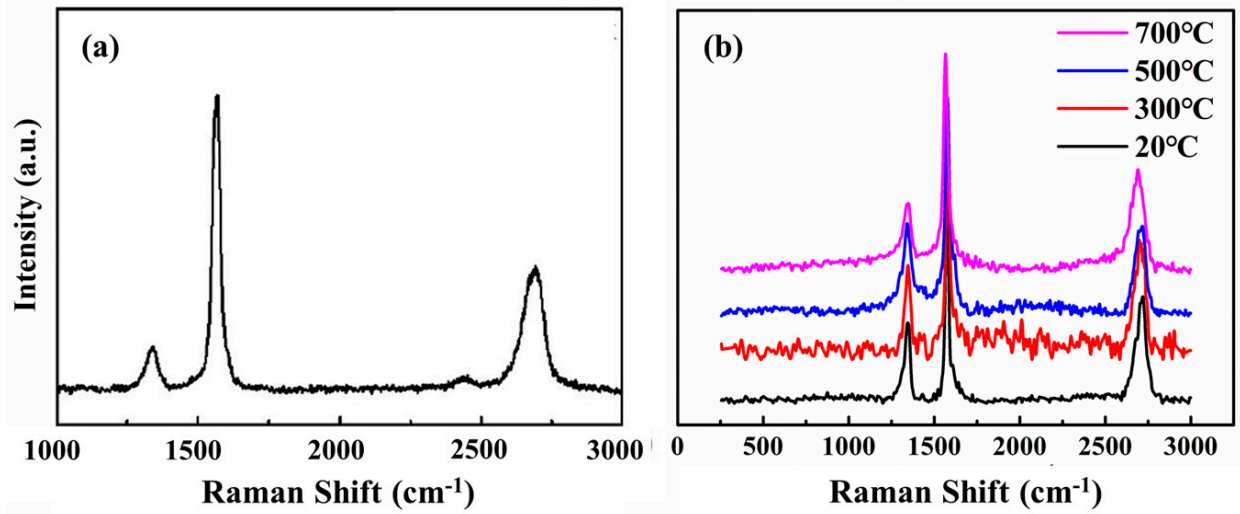

Figure 2. Raman characterization of $0.6 \mathrm{wt}$.\% graphene/Cu composites before and after rolling at different temperature. (a) Composite before rolling, (b) Composite rolled at different temperature. 
After rolling at different temperatures, the graphene changes significantly. Comparing the positions of the characteristic peaks of the Raman spectrum curve at different rolling temperatures, it can be seen that the positions of the D peak and the G peak are basically the same. The peak shape of the 2D peak changes slightly due to the change in the number of graphene layers. The ratio of the intensity of change of the graphene D peak, the G peak, and the $2 \mathrm{D}$ peak is quantified, as shown in Figure 3.
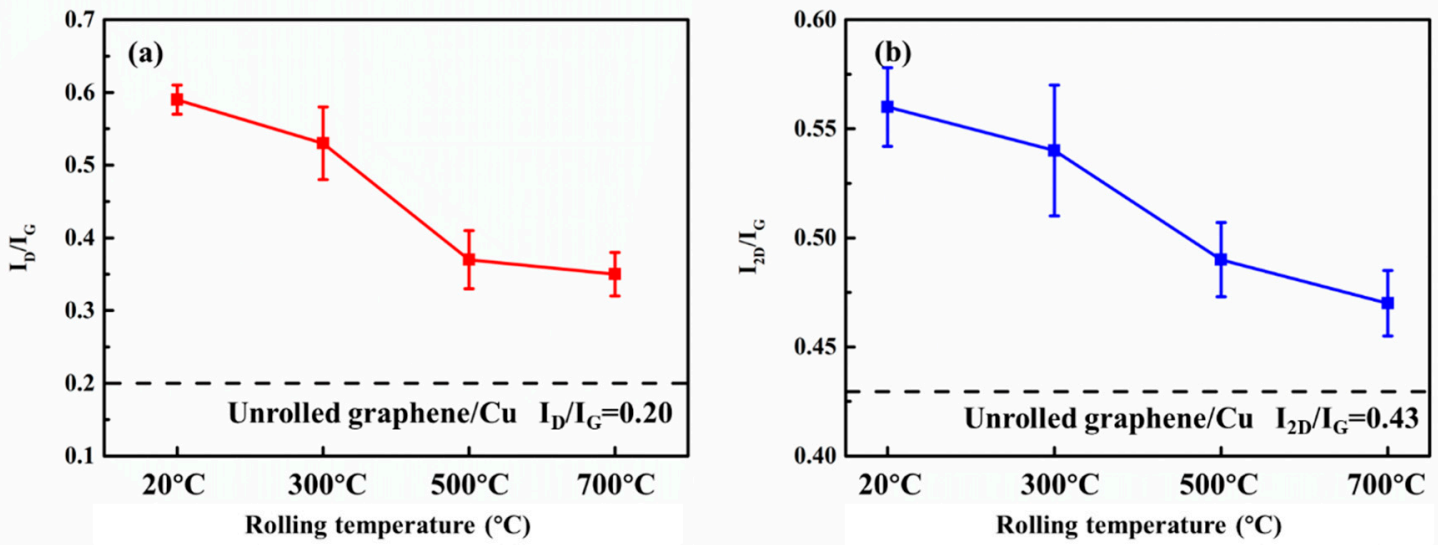

Figure 3. Quantitative statistics of Raman peak intensity of rolled composites at different temperatures. (a) $\mathrm{I}_{\mathrm{D}} / \mathrm{I}_{\mathrm{G}}$, (b) $\mathrm{I}_{2 \mathrm{D}} / \mathrm{I}_{\mathrm{G}}$.

It can be seen that when the composites were rolled, the $\mathrm{I}_{\mathrm{D}} / \mathrm{I}_{\mathrm{G}}$ of graphene increased significantly compared to the unrolled graphene/Cu composites, indicating a significant increase in the defect content in graphene. Graphene suffers huge damage during the rolling process. $\mathrm{I}_{2 \mathrm{D}} / \mathrm{I}_{\mathrm{G}}$ also increased slightly, indicating that the number of graphene layers decreased during the rolling process.

As the rolling temperature rises, $\mathrm{I}_{\mathrm{D}} / \mathrm{I}_{\mathrm{G}}$ and $\mathrm{I}_{2 \mathrm{D}} / \mathrm{I}_{\mathrm{G}}$ drops slightly. It shows that after the rolling temperature is increased, the rolling damage to the graphene is less, and at the same time, the peeling effect of the graphene is reduced. This is because when the rolling temperature is lower, the composite is subjected to greater stress during cold rolling. Graphene shears, bends, and twists as the substrate deforms, creating more edge and hole defects. At the same time, the large shear stress also causes the multi-layer graphene layer to slip, which reduces the number of graphene layers. To further characterize the changes in the number of graphene layers at different rolling temperatures, the deviation of the graphene $G$ peak and 2D peak is observed, as shown in the Figure 4.
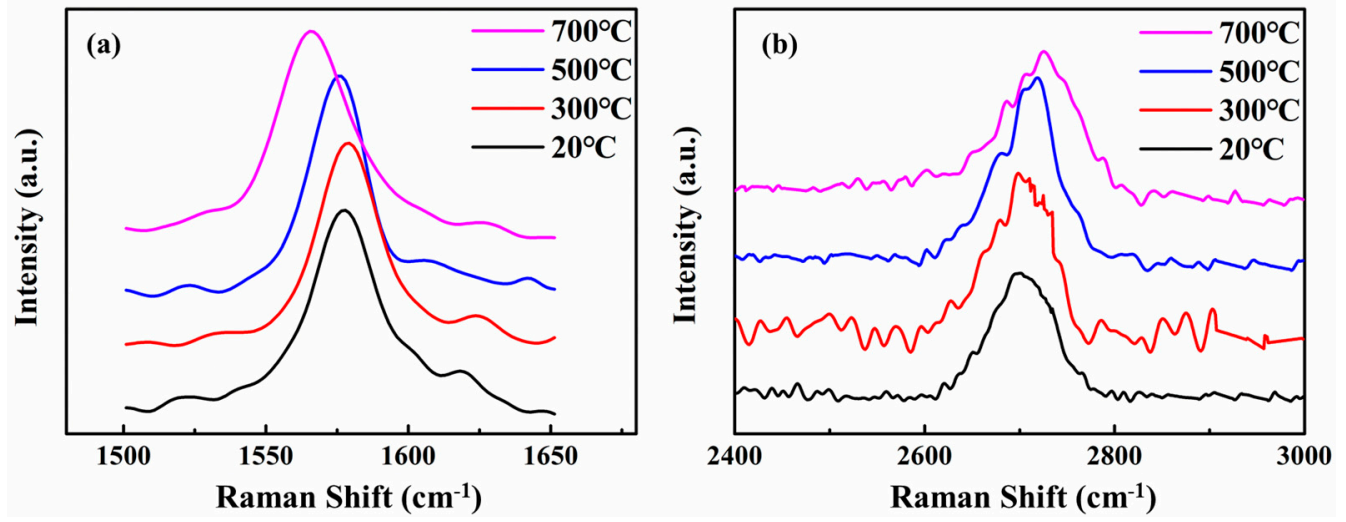

Figure 4. The peak shapes of $G$ peak and 2D peak under different rolling temperatures. (a) G peaks, (b) 2D peaks.

Based on the research results of Malard et al. [33], as the number of graphene layers decreases, the $2 \mathrm{D}$ peak wave number decreases. If the $\mathrm{G}$ peak is used as a reference, the 
greater the wavenumber difference between the 2D peak and the $G$ peak, the greater the number of graphene layers. It can be seen from Figure 4 that as the rolling temperature decreases, the $G$ peak shifts to the right and the 2D peak shifts to the left. As the rolling temperature decreases, the number of graphene layers decreases. The lower the rolling temperature, the more obvious the graphene thinning. The $\mathrm{D}$ peak position of the composite rolled at $20^{\circ} \mathrm{C}$ is $2696 \mathrm{~cm}^{-1}$. Based on the results reported in other papers [32,33], it can be seen that the number of graphene layers has dropped below 3 layers. It shows that rolling has a significant shearing and exfoliation effect on graphene, and has an important contribution to the reduction of graphene in the $\mathrm{Cu}$ matrix.

\subsection{The Influence of Rolling Deformation on Structure of Graphene}

At $700{ }^{\circ} \mathrm{C}$, under the condition of $10 \%$ deformation in a single press, the composite is subjected to multiple rolling treatments. The total rolling deformation is $4.0 \mathrm{~mm} \rightarrow 10 \%$ $(3.6 \mathrm{~mm}) \rightarrow 20 \%(3.2 \mathrm{~mm}) \rightarrow 30 \%(2.8 \mathrm{~mm}) \rightarrow 60 \%(2.4 \mathrm{~mm}) \rightarrow 50 \%(2.0 \mathrm{~mm}) \rightarrow 60(1.6 \mathrm{~mm})$ $\rightarrow 70 \%(1.2 \mathrm{~mm}) \rightarrow 80 \%(0.8 \mathrm{~mm})$. The Raman characterization of rolled composites with different deformations is performed, and the results are shown in Figure $5 a, b$.
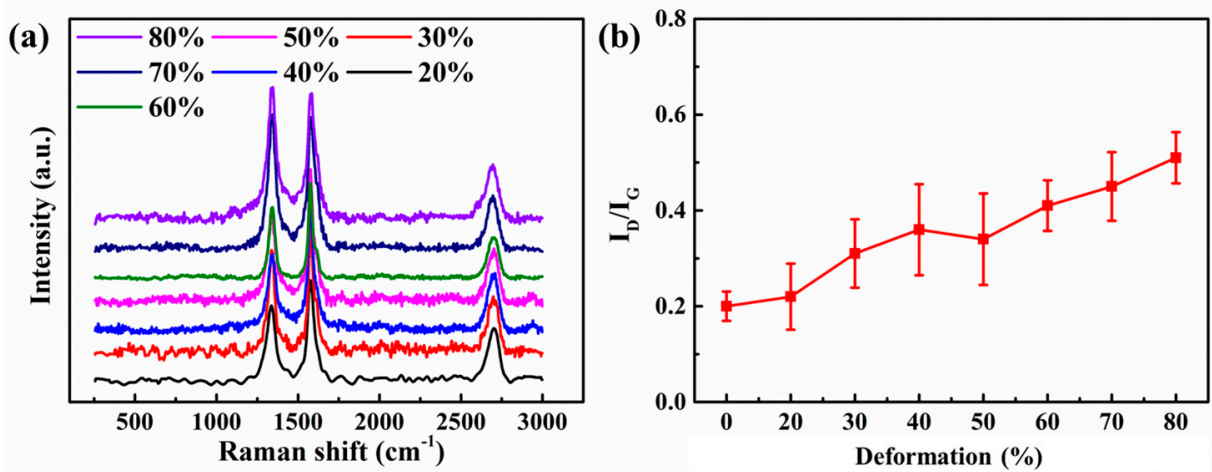

Figure 5. Raman characterization of $0.6 \mathrm{wt}$.\% graphene/Cu composites at different rolling deformation. (a) Results of Raman characterization, (b) Quantitative statistics of $\mathrm{I}_{\mathrm{D}} / \mathrm{I}_{\mathrm{G}}$ peak intensity.

The intensity ratio of the D peak and the G peak is quantitatively calculated to determine the state of graphene defects, as shown in Figure $5 \mathrm{~b}$. The $\mathrm{I}_{\mathrm{D}} / \mathrm{I}_{\mathrm{G}}$ ratio of different total deformations has shown an upward trend from $20 \%$ to $80 \%$, indicating that the defects of graphene are gradually increasing during the rolling process. At the beginning of rolling, the value of $\mathrm{I}_{\mathrm{D}} / \mathrm{I}_{\mathrm{G}}$ has a large standard deviation value, indicating that the structure is not uniform in the initial stage of deformation. When the total deformation is $40 \%$, the standard deviation values of the $\mathrm{I}_{\mathrm{D}} / \mathrm{I}_{\mathrm{G}}$ ratio begin to decrease, indicating that the change of graphene begins to stabilize. As the rolling deformation continues, when the total deformation reaches $70 \%$, the $\mathrm{I}_{\mathrm{D}} / \mathrm{I}_{\mathrm{G}}$ ratio once again greatly increases. The graphene defects increase significantly, and the variance of the $\mathrm{I}_{\mathrm{D}} / \mathrm{I}_{\mathrm{G}}$ ratio continues to increase. It showed that in the later stage of rolling deformation, under the action of large deformation, the $\mathrm{Cu}$ matrix began to crack, and stress concentration was formed at the crack during the deformation, which caused more serious damage to the graphene near the crack.

The shift of graphene $G$ and 2D peaks in rolled composites with different deformations was observed, as shown in Figure 6. It can be seen that as the number of deformations increases, the position of the $G$ peak does not change significantly, while the 2D peak shifts to the low wavenumber direction. It can be seen from the results that as the amount of rolling deformation increases, the number of graphene layers decreases. The reason for graphene thinning is the same as the previous study. As the matrix deforms, graphene slips between layers and the number of layers decreases. 

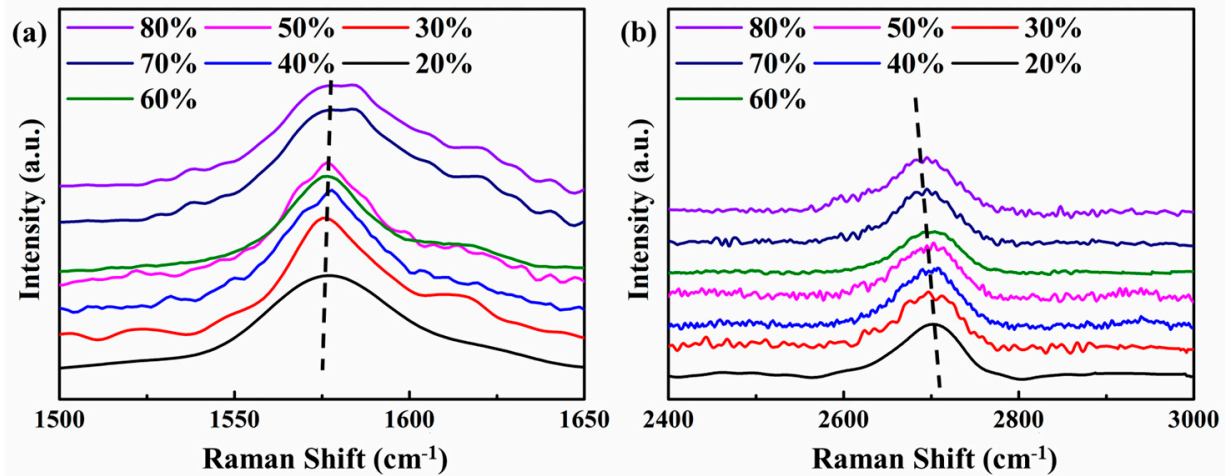

Figure 6. The peak shapes of $G$ peak and 2D peak under different rolling deformation. (a) G peaks, (b) 2D peaks.

\subsection{Relative Density and Microstructure of Composites Obtained under Different Rolling Parameters}

To further study the change law of the composite microstructure and explain the abnormal rise of graphene defects after the deformation exceeds $70 \%$ during cold rolling, the relative density and microstructure of the composite are characterized.

The relative density of the composite rolled at different temperatures and different deformation amounts are shown in Figure 7. It can be seen that there are differences in the relative density of composites rolled at different temperatures. When the rolling temperature is higher $\left(500-700^{\circ} \mathrm{C}\right)$, the relative density of the composite is slightly higher than that of low-temperature rolling $\left(20-300{ }^{\circ} \mathrm{C}\right)$. This is because the $\mathrm{Cu}$ matrix is more prone to deformation under high-temperature conditions. And the defects such as pores and cracks are eliminated during the rolling process, increasing the density of composites. With the increase in rolling deformation, the relative density is on the rise. When the deformation exceeds $70 \%$, the density of the low-temperature rolled composite will be greatly attenuated, while the density of the high-temperature rolled composite material will increase slightly.

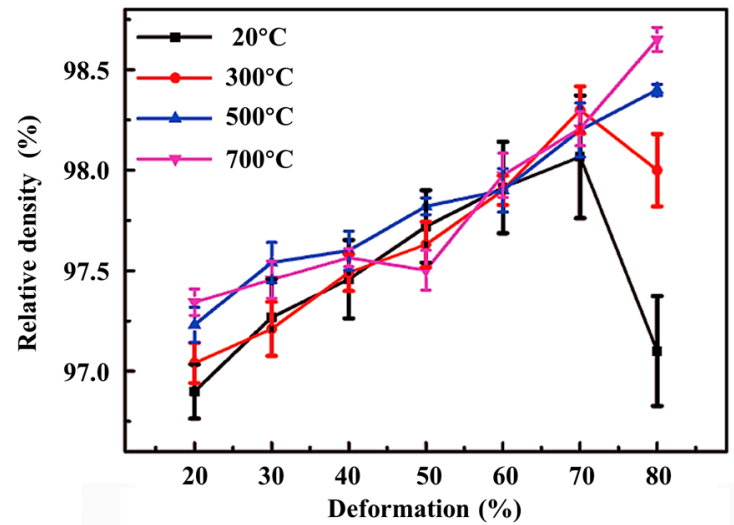

Figure 7. Relative density of composites rolled at different temperatures and deformations.

SEM observation is performed on the $0.6 \mathrm{wt}$.\% graphene $/ \mathrm{Cu}$ composite rolled at $20{ }^{\circ} \mathrm{C}$, and the reason for the decrease in density is analyzed, as shown in Figure 8. Figure 8a is a sample with $30 \%$ deformation. It can be seen that there are a few cracks and holes, as shown by the yellow arrow. As the rolling amount increases, the cracks gradually disappear, and the relative density increases. Figure $8 \mathrm{c}$ shows a sample with $80 \%$ deformation. When the deformation is too large, a large number of cracks and holes reappear in the material. When the rolling temperature is low, dislocations do not move easily, resulting in a $\mathrm{Cu}$ matrix that is not easily deformed. At higher rolling deformation, the matrix will directly crack and produce pores, resulting in a significant decrease in the density of the composite. 
(a)

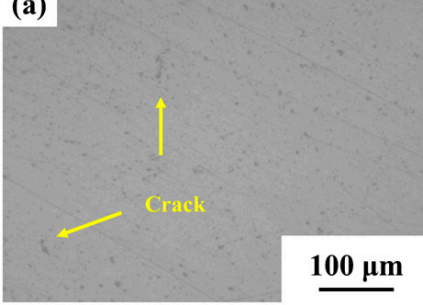

(b)

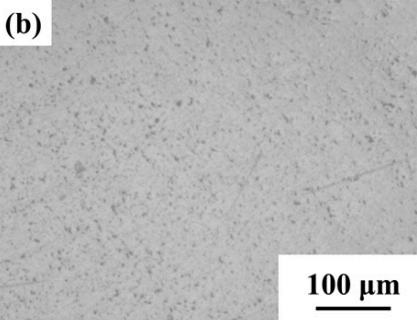

(c)

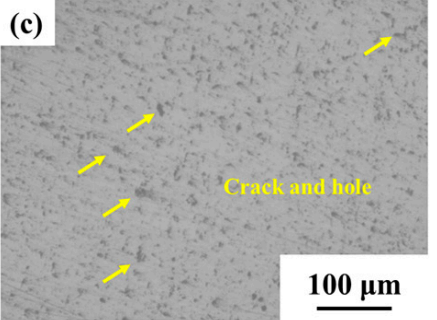

Figure 8. SEM characterization of $0.6 \mathrm{wt}$.\% graphene/Cu composites under different deformations. (a) $30 \%$, (b) $50 \%$, (c) $80 \%$

\subsection{Hardness and Electrical Properties of Composites Obtained under Different Rolling Parameters}

The hardness test of the composite after rolling treatment at different temperatures and deformations is shown in Figure 9. It can be seen that the composite obtained by rolling at $20{ }^{\circ} \mathrm{C}$ has the highest hardness. As the deformation increases, the hardness increases from $95 \mathrm{HV}$ to $131 \mathrm{HV}$. When the amount of deformation reaches $80 \%$, the hardness drops significantly to $105 \mathrm{HV}$. The hardness of the composite rolled at $700{ }^{\circ} \mathrm{C}$ is lower than $20^{\circ} \mathrm{C}$. As the amount of deformation increases, the hardness increases from $81 \mathrm{HV}$ to $110 \mathrm{HV}$, and the hardness has not decreased when the deformation exceeds $80 \%$.

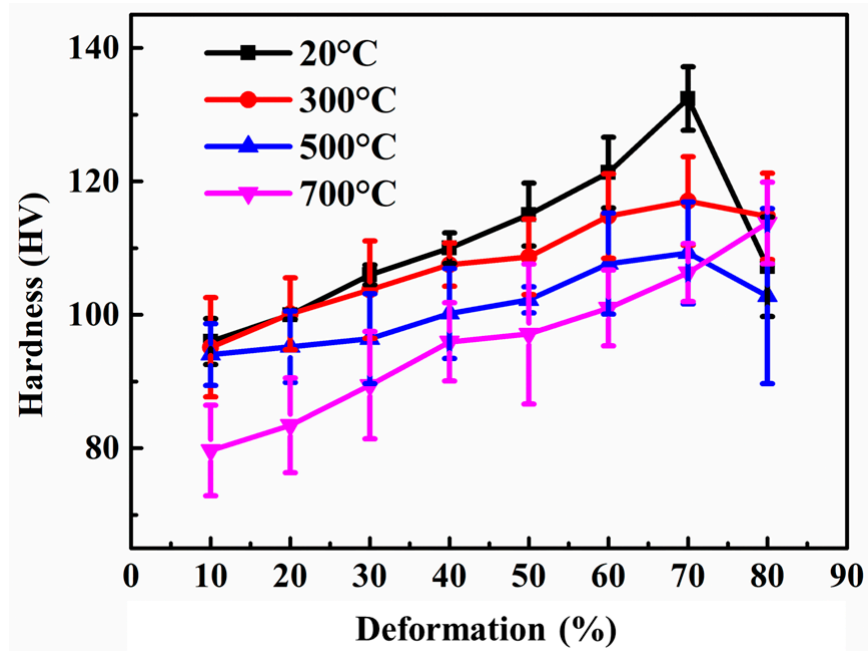

Figure 9. Hardness characterization of $0.6 \mathrm{wt}$ \% graphene/Cu composites under different temperatures and deformations.

Combining the density and the Raman characterization, the reasons for the performance changes can be analyzed. When the amount of rolling deformation is low, as the amount of deformation increases, the agglomerated multilayer graphene is thinned, and the matrix defects are reduced, increasing the hardness of the composite. When the deformation exceeds $70 \%$, the $\mathrm{Cu}$ matrix will crack and the graphene will be severely broken, which will degrade the properties of composites. The performance after rolling shows an overall downward trend as the temperature increases. Combined with the Raman characterization, it can be seen that when the rolling temperature is lower, the matrix has greater stress, so the graphene has a more obvious thinning effect. At the same time, the graphene is more uniformly dispersed, and the strengthening ability is more easily exerted. Therefore, the material has greater hardness when rolled at low-temperature. The change in the properties of the composites was also related to the change in $\mathrm{Cu}$ grain size. It was reported that the $\mathrm{Cu}$ matrix grains were found to be coarse at higher rolling temperatures and the material properties decreased substantially [36-38]. In addition, the degree of graphene dispersion is higher and more uniform at low temperature rolling. Fei [39-41] and Zhao [14,42] et al. found that graphene has a hindering effect on the movement of dislocations in the metal 
matrix. When the degree of graphene dispersion is higher, the locking effect on dislocations is more obvious, which also contributes more to the hardness enhancement of the material.

Afterward, the electrical conductivity of the composites rolled at different temperatures and deformations is tested, and the results are shown in Figure 10. The measured conductivity result is expressed by IACS (International Annealed Copper Standard). It can be seen that the change law of conductivity is opposite to that of hardness. When rolled at $700{ }^{\circ} \mathrm{C}$, the rolled composite has a higher electrical conductivity. As the amount of deformation increases, the electrical conductivity increases from 83.7 IACS\% to 95.2 IACS\%. The conductivity of the sample rolled at $20{ }^{\circ} \mathrm{C}$ is lower, increasing from $82.5 \mathrm{IACS} \%$ to 89.6 IACS\%. When the deformation reaches $80 \%$, the electrical conductivity of the lowtemperature rolled samples also appears to be greatly reduced, which is related to the reduction of density and graphene fragmentation.

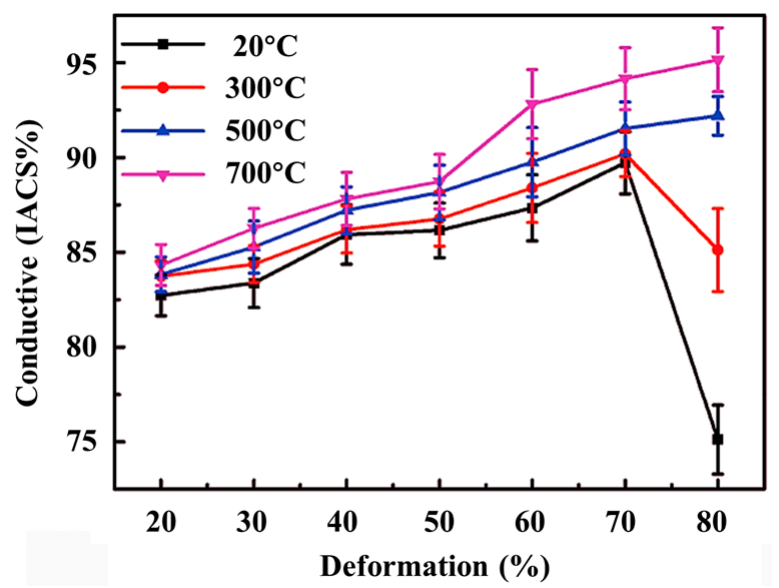

Figure 10. Conductive characterization of $0.6 \mathrm{wt} . \%$ graphene/Cu composites under different temperatures and deformations.

As the rolling temperature increases, the conductivity of the composite increases. Based on previous studies, it can be seen that the higher the rolling temperature, the less damage the rolling will cause to graphene. Low-damage graphene has more contribution to electrical conductivity, so the electrical conductivity of composites prepared by hightemperature rolling is higher. The conductivity is also related to the grain size of the $\mathrm{Cu}$ matrix, the larger the grain size and the less grain boundary content, the higher the conductivity [43]. The grain size of the $\mathrm{Cu}$ matrix is larger during high temperature rolling and therefore also contributes positively to the electrical conductivity of the material.

In addition, rolling can produce an oriented arrangement of graphene in the composite. Guo et al. [44] investigated the properties of directionally aligned graphene/A18030 composites and found that the yield strength, tensile strength, and electrical conductivity of the materials were substantially increased in the direction of the directional alignment of graphene. When the graphene/ $\mathrm{Al}$ composites fracture, microcracks preferentially arise from the weak interface between the GNPs and the matrix. Then the cracks extend into the grains and deflect when they encounter the next GNPs. Finally, the cracks gradually extend until fracture. Directionally aligned graphene can create more obstacles for crack extension, which greatly enhances the path of crack movement when the material fractures and is an important reason for the material to maintain plasticity and increase strength.

\section{Conclusions}

In this work, the microstructure and properties under different rolling temperatures and rolling deformation were systematically investigated. When the rolling temperature decreases and the deformation increases, the thinning effect of graphene during rolling is enhanced, and more damage to graphene is also produced. At rolling temperatures below $300{ }^{\circ} \mathrm{C}$, rolling facilitates the uniform dispersion of few-layer graphene in the $\mathrm{Cu}$ matrix. 
When the temperature is higher than $300^{\circ} \mathrm{C}$, the damaging effect of rolling on graphene can be reduced.

The hardness and electrical conductivity of the composites increased with the increase of rolling deformation. When the deformation of low-temperature rolling exceeds $70 \%$, its properties are weakened. The hardness of the composites decreases with increasing rolling temperature, while the electrical conductivity increases with increasing rolling temperature. In this paper, the structural and property changes of the composites under different rolling processes are comprehensively studied to provide a reference for the rolling process of graphene/copper composites with different demands.

Author Contributions: Conceptualization, Z.X.; Data curation, Z.X. and B.J.; Formal analysis, J.L., J.Z. and Y.G.; Funding acquisition, W.Y.; Investigation, B.J., Z.W. and Y.F.; Methodology, J.L., N.Z. and Y.G.; Project administration, Y.F. and Q.Z.; Resources, B.J. and N.Z.; Supervision, Y.M., Z.W. and P.K.; Validation, Y.M., Q.Z. and J.Z.; Writing-original draft, Z.X., Z.W. and N.Z.; Writingreview \& editing, B.J., P.K. and W.Y. All authors have read and agreed to the published version of the manuscript.

Funding: This research is funded by the Excellent Youth Scholars project of Natural Science Foundation of Heilongjiang Province (YQ2021E016).

Institutional Review Board Statement: Not applicable.

Informed Consent Statement: Not applicable.

Data Availability Statement: The data presented in this study are available on request from the corresponding author.

Conflicts of Interest: The authors declare no conflict of interest.

\section{References}

1. Cao, M.; Xiong, D.-B.; Tan, Z.; Ji, G.; Amin-Ahmadi, B.; Guo, Q.; Fan, G.; Guo, C.; Li, Z.; Zhang, D. Aligning graphene in bulk copper: Nacre-inspired nanolaminated architecture coupled with in-situ processing for enhanced mechanical properties and high electrical conductivity. Carbon 2017, 117, 65-74. [CrossRef]

2. Chen, X.; Tao, J.; Liu, Y.; Bao, R.; Li, F.; Li, C.; Yi, J. Interface interaction and synergistic strengthening behavior in pure copper matrix composites reinforced with functionalized carbon nanotube-graphene hybrids. Carbon 2019, 146, 736-755. [CrossRef]

3. Behera, A.K.; Mallik, A. Ultrasound assisted electroplating of nano-composite thin film of Cu matrix with electrochemically in-house synthesized few layer graphene nano-sheets as reinforcement. J. Alloys Compd. 2018, 750, 587-598. [CrossRef]

4. Wang, J.; Zhang, X.; Zhao, N.; He, C. In situ synthesis of copper-modified graphene-reinforced aluminum nanocomposites with balanced strength and ductility. J. Mater. Sci. 2018, 54, 5498-5512. [CrossRef]

5. Wang, S.; Han, S.; Xin, G.; Lin, J.; Wei, R.; Lian, J.; Sun, K.; Zu, X.; Yu, Q. High-quality graphene directly grown on Cu nanoparticles for Cu-graphene nanocomposites. Mater. Des. 2018, 139, 181-187. [CrossRef]

6. Lee, C.; Wei, X.; Kysar, J.W.; Hone, J. Measurement of the elastic properties and intrinsic strength of monolayer graphene. Science 2008, 321, 385-388. [CrossRef]

7. Liu, P.; Xie, J.; Wang, A.; Ma, D.; Mao, Z. First-principles prediction of enhancing graphene/Al interface bonding strength by graphene doping strategy. Appl. Surf. Sci. 2020, 517, 146040. [CrossRef]

8. Ge, X.; Klingshirn, C.; Morales, M.; Wuttig, M.; Rabin, O.; Zhang, S.; Salamanca-Riba, L.G. Electrical and structural characterization of nano-carbon-aluminum composites fabricated by electro-charging-assisted process. Carbon 2021, 173, 115-125. [CrossRef]

9. Ghazanlou, S.I.; Eghbali, B.; Petrov, R. Study on the microstructural and texture evolution of Hot Rolled Al7075/ graphene/ carbon nanotubes reinforced composites. Mater. Chem. Phys. 2021, 257, 123766. [CrossRef]

10. Han, R.Q.; Song, H.Y.; Wang, J.Y.; Li, Y.L. Strengthening mechanism of Al matrix composites reinforced by nickel-coated graphene: Insights from molecular dynamics simulation. Physica B 2021, 601, 412620. [CrossRef]

11. Shi, Z.; Sheng, J.; Yang, Z.; Liu, Z.; Chen, S.; Wang, M.; Wang, L.; Fei, W. Facile synthesis of high-performance carbon nanosheet/Cu composites from copper formate. Carbon 2020, 165, 349-357. [CrossRef]

12. Zhang, Q.; Yi, Z.; Liu, Y.; Han, P.; Mei, J. Understanding heterogeneous metal-mediated interfacial enhancement mechanisms in graphene-embedded copper matrix composites. Appl. Surf. Sci. 2021, 541, 148524. [CrossRef]

13. Dong, L.L.; Fu, Y.Q.; Liu, Y.; Lu, J.W.; Zhang, W.; Huo, W.T.; Jin, L.H.; Zhang, Y.S. Interface engineering of graphene/copper matrix composites decorated with tungsten carbide for enhanced physico-mechanical properties. Carbon 2021, 173, 41-53. [CrossRef]

14. Yang, M.; Liu, Y.; Fan, T.; Zhang, D. Metal-graphene interfaces in epitaxial and bulk systems: A review. Prog. Mater Sci. 2020, 110, 100652. [CrossRef] 
15. Zhang, X.; Yang, W.; Zhang, J.; Ge, X.; Liu, X.; Zhan, Y. Multiscale graphene/carbon fiber reinforced copper matrix hybrid composites: Microstructure and properties. Mater. Sci. Eng. A 2019, 743, 512-519. [CrossRef]

16. Damm, C.; Nacken, T.J.; Peukert, W. Quantitative evaluation of delamination of graphite by wet media milling. Carbon 2015, 81, 284-294. [CrossRef]

17. Zhang, X.; Xu, Y.; Wang, M.; Liu, E.; Zhao, N.; Shi, C.; Lin, D.; Zhu, F.; He, C. A powder-metallurgy-based strategy toward three-dimensional graphene-like network for reinforcing copper matrix composites. Nat. Commun. 2020, 11, 2775. [CrossRef]

18. Zhou, W.; Sasaki, S.; Kawasaki, A. Effective control of nanodefects in multiwalled carbon nanotubes by acid treatment. Carbon 2014, 78, 121-129. [CrossRef]

19. Han, T.; Li, J.; Zhao, N.; He, C. Microstructure and properties of copper coated graphene nanoplates reinforced Al matrix composites developed by low temperature ball milling. Carbon 2020, 159, 311-323. [CrossRef]

20. Shao, P.; Chen, G.; Ju, B.; Yang, W.; Zhang, Q.; Wang, Z.; Tan, X.; Pei, Y.; Zhong, S.; Hussain, M.; et al. Effect of hot extrusion temperature on graphene nanoplatelets reinforced Al6061 composite fabricated by pressure infiltration method. Carbon 2020, 162, 455-464. [CrossRef]

21. Shao, P.; Yang, W.; Zhang, Q.; Meng, Q.; Tan, X.; Xiu, Z.; Qiao, J.; Yu, Z.; Wu, G. Microstructure and tensile properties of 5083 Al matrix composites reinforced with graphene oxide and graphene nanoplates prepared by pressure infiltration method. Compos. Part A Appl. Sci. Manuf. 2018, 109, 151-162. [CrossRef]

22. Wu, G.; Yu, Z.; Jiang, L.; Zhou, C.; Deng, G.; Deng, X.; Xiao, Y. A novel method for preparing graphene nanosheets/Al composites by accumulative extrusion-bonding process. Carbon 2019, 152, 932-945. [CrossRef]

23. Huang, C.-y.; Hu, S.-p.; Chen, K. Influence of rolling temperature on the interfaces and mechanical performance of graphenereinforced aluminum-matrix composites. Int. J. Miner. Metall. Mater. 2019, 26, 752-759. [CrossRef]

24. Wang, M.; Sheng, J.; Wang, L.-D.; Yang, Z.-Y.; Shi, Z.-D.; Wang, X.-J.; Fei, W.-D. Hot rolling behavior of graphene/Cu composites. J. Alloys Compd. 2020, 816, 153204. [CrossRef]

25. Korznikova, G.; Czeppe, T.; Khalikova, G.; Gunderov, D.; Korznikova, E.; Litynska-Dobrzynska, L.; Szlezynger, M. Microstructure and mechanical properties of $\mathrm{Cu}$-graphene composites produced by two high pressure torsion procedures. Mater. Charact. 2020, 161, 110122. [CrossRef]

26. Yao, G.C.; Mei, Q.S.; Li, J.Y.; Li, C.L.; Ma, Y.; Chen, F.; Liu, M. Cu/C composites with a good combination of hardness and electrical conductivity fabricated from $\mathrm{Cu}$ and graphite by accumulative roll-bonding. Mater. Des. 2016, 110, 124-129. [CrossRef]

27. Tiwari, J.K.; Mandal, A.; Rudra, A.; Mukherjee, D.; Sathish, N. Evaluation of mechanical and thermal properties of bilayer graphene reinforced aluminum matrix composite produced by hot accumulative roll bonding. J. Alloys Compd. 2019, 801, 49-59. [CrossRef]

28. Liu, X.; Wei, D.; Zhuang, L.; Cai, C.; Zhao, Y. Fabrication of high-strength graphene nanosheets/Cu composites by accumulative roll bonding. Mater. Sci. Eng. A 2015, 642, 1-6. [CrossRef]

29. Ferrari, A.C.; Robertson, J. Resonant Raman spectroscopy of disordered, amorphous, and diamondlike carbon. Phys. Rev. B 2001, 64, 075414. [CrossRef]

30. Mohiuddin, T.M.G.; Lombardo, A.; Nair, R.R.; Bonetti, A.; Savini, G.; Jalil, R.; Bonini, N.; Basko, D.M.; Galiotis, C.; Marzari, N.; et al. Uniaxial strain in graphene by Raman spectroscopy:Gpeak splitting, Grüneisen parameters, and sample orientation. Phys. Rev. B 2009, 79, 075414. [CrossRef]

31. Huang, B.-R.; Chan, H.-W.; Jou, S.; Chen, G.-Y.; Kuo, H.-A.; Song, W.-J. Structure and field emission of graphene layers on top of silicon nanowire arrays. Appl. Surf. Sci. 2016, 362, 250-256. [CrossRef]

32. Lee, J.; Novoselov, K.S.; Shin, H.S. Interaction between Metal and Graphene: Dependence on the Layer Number of Graphene. ACS Nano 2011, 5, 608-612. [CrossRef] [PubMed]

33. Malard, L.M.; Pimenta, M.A.; Dresselhaus, G.; Dresselhaus, M.S. Raman spectroscopy in graphene. Phys. Rep. 2009, 473, 51-87. [CrossRef]

34. Wu, J.; Xu, H.; Zhang, J. Raman Spectroscopy of Graphene. Acta Chim. Sinica 2014, 72, 301-318. [CrossRef]

35. Ju, B.; Yang, W.; Zhang, Q.; Hussain, M.; Xiu, Z.; Qiao, J.; Wu, G. Research progress on the characterization and repair of graphene defects. Int. J. Min. Met. Mater. 2020, 27, 1179-1190. [CrossRef]

36. San, X.Y.; Liang, X.G.; Cheng, L.P.; Li, C.J.; Zhu, X.K. Temperature effect on mechanical properties of Cu and Cu alloys. Mater. Des. 2012, 35, 480-483. [CrossRef]

37. Li, W.; Shen, Y.; Xie, C. High thermal stability of submicron grained Cu processed by asymmetrical rolling. Mater. Des. 2016, 105, 404-410. [CrossRef]

38. Fu, H.; Xu, S.; Li, W.; Xie, J.; Zhao, H.; Pan, Z. Effect of rolling and aging processes on microstructure and properties of Cu-Cr-Zr alloy. Mater. Sci. Eng. A 2017, 700, 107-115. [CrossRef]

39. Shuang, F.; Aifantis, K.E. Dislocation-graphene interactions in $\mathrm{Cu}$ /graphene composites and the effect of boundary conditions: A molecular dynamics study. Carbon 2021, 172, 50-70. [CrossRef]

40. Shuang, F.; Aifantis, K.E. Modelling dislocation-graphene interactions in a BCC Fe matrix by molecular dynamics simulations and gradient plasticity theory. Appl. Surf. Sci. 2021, 535, 147602. [CrossRef]

41. Shuang, F.; Dai, Z.H.; Aifantis, K.E. Strengthening in Metal/Graphene Composites: Capturing the Transition from Interface to Precipitate Hardening. ACS Appl. Mat. Interfaces 2021, 13, 26610-26620. [CrossRef] [PubMed] 
42. Zhao, L.; Guo, Q.; Li, Z.; Li, Z.; Fan, G.; Xiong, D.-B.; Su, Y.; Zhang, J.; Tan, Z.; Zhang, D. Strain-rate dependent deformation mechanism of graphene-Al nanolaminated composites studied using micro-pillar compression. Int. J. Plast 2018, 105, 128-140. [CrossRef]

43. Zhu, D.-C.; Tang, K.; Song, M.-z.; Tu, M.-j. Effects of annealing process on electrical conductivity and mechanical property of $\mathrm{Cu}-\mathrm{Te}$ alloys. Trans. Nonferrous Met. Soc. China 2006, 16, 459-462. [CrossRef]

44. Guo, Y.; Yi, D.; Liu, H.; Wang, B.; Jiang, B.; Wang, H. Mechanical properties and conductivity of graphene/Al-8030 composites with directional distribution of graphene. J. Mater. Sci. 2019, 55, 3314-3328. [CrossRef] 